\title{
ACTIVATION PARAMETERS AND EXCESS THERMODYANAMIC FUNCTIONS OF HYDROXAMIC ACIDS IN ACETONE - WATER MIXTURE AT 303.15 K AND 313.15 K: A VISCOMETRIC APPROACH
}

\author{
Ajita Dixit and Rama Pande*
}

School of Studies in Chemistry, Pt. Ravishankar Shukla University, Raipur (C.G.) 492010, India

(Received November 1, 2005; revised May 22, 2007)

\begin{abstract}
Experimental values of density and viscosity of $\mathrm{N}$-arylsubstituted hydroxamic acids were evaluated at $\mathrm{T}=303.15 \mathrm{~K}$ and $313.15 \mathrm{~K}$ in acetone-water mixture as a function of their concentration. The properties of solutes were obtained as an intercept of plots $C$ vs $\eta$ of solutions. Applying these data, viscosity- $B$ coefficients, activation parameters $\left(\Delta \mu_{1}{ }^{0 \neq}\right)$ and $\left(\Delta \mu_{2}{ }^{0 \neq}\right)$ and excess thermodynamic functions, viz., excess molar volume $\left(\mathrm{V}^{\mathrm{E}}\right)$, excess viscosity, $\left(\eta^{\mathrm{E}}\right)$ and excess molar free energy of activation of flow, $\left(\mathrm{G}^{\mathrm{E}}\right)$ were calculated. The value of interaction parameter, $\mathrm{d}$, of Grunberg and Nissan expression have also been calculated and reported. Analysis of these data suggests that specific interactions are present in the system.
\end{abstract}

KEY WORDS: Activation parameters, N-Arylsubstituted hydroxamic acids, Density, Viscosity, Viscosity- $B$ coefficients, Excess viscosity

\section{INTRODUCTION}

The thermodynamic and transport properties of molecules and their solutions are important to understand the molecular interactions. Hydroxamic acids behave like non-electrolytes and found in nature [1] and can be synthesised in laboratory [2]. All natural hydroxamic acids with ferric trihydroxamate center act as iron transfer agents and are designated as siderochromes [1]. Hydroxamic acids are wide-spread in the tissues of plants and play an important role in the detoxification of toxic host plants [3,4] and in iron acquisition of grasses [5, 6]. These are detected in rye, maize, rice and wheat seedlings [7, 8] and also reported to be active as herbicides [9] and pesticides [10]. Ferrichrome XV and XVI are found in Japanese sake [11] and account for part of its yellow colour. Hydroxamic acids are used as cultivator in corn seedlings to reduce water potential before, during and after germination [12]. Knowledge of transport properties of hydroxamic acids is important in all these applications to understand the molecular interactions. Very little work is done in this direction. Therefore, as an extension of our earlier work [13], the viscosity of two hydroxamic acids in acetone-water mixture $50 \%(\mathrm{v} / \mathrm{v})$ were obtained at $303.15 \mathrm{~K}$ and $313.15 \mathrm{~K}$ as a function of their concentration. Another equally important quantity which is often required to determine the viscosity, is the density, $\rho$. The density data were also measured under the same conditions. The other related useful parameters evaluated are, viscosity- $B$-coefficients, activation parameters, $\left(\Delta \mu_{1}{ }^{0 \neq}\right.$ and $\left.\Delta \mu_{2}{ }^{0 \neq}\right)$ and excess thermodynamic properties, excess molar volume $\left(\mathrm{V}^{\mathrm{E}}\right)$, excess viscosity $\left(\eta^{\mathrm{E}}\right)$ and excess molar free energy of activation of flow $\left(\mathrm{G}^{\mathrm{E}}\right)$ of these molecules.

\section{EXPERIMENTAL}

Two hydroxamic acids (N-p-tolylbenzo, $p$ - $\mathrm{CH}_{3} \cdot \mathrm{C}_{6} \mathrm{H}_{4} \mathrm{NOHC}_{6} \mathrm{H}_{5} \mathrm{C}=\mathrm{O}$ and $\mathrm{N}$-o-tolylbenzo, $o$ $\mathrm{CH}_{3} \cdot \mathrm{C}_{6} \mathrm{H}_{4} \mathrm{NOH} . \mathrm{C}_{6} \mathrm{H}_{5} \mathrm{C}=\mathrm{O}$ ) were selected for the present investigation. These were synthesised in the laboratory following the method reported in literature [2] and were purified by crystallisation thrice with benzene. The purity of compounds was ascertained by determining their melting points, UV and IR spectra. The data obtained were tallied with reported values.

*Corresponding author. E-mail: rama_pande10@yahoo.com 
Stock solution of $0.05 \mathrm{M}$ was prepared by dissolving hydroxamic acid in $100 \mathrm{~mL}$ of $50 \%$ (v/v) acetone-water mixed solvent. Mass dilution technique was applied to prepare the solution of different concentration ranged from $0.01 \mathrm{M}$ to $0.05 \mathrm{M}$. Densities of hydroxamic acid solutions in mixed solvent were determined using $10 \mathrm{~mL}$ double armed pycnometer at temperatures $303.15 \mathrm{~K}$ and $313.15 \mathrm{~K}$. The pycnometer was calibrated at these temperatures with distilled water and benzene. The estimated accuracy of density measurement of solution was $\pm 0.00003 \mathrm{~g} \mathrm{~mL}^{-1}$.

Viscosities were measured by thermostated capillary viscometer of Ostwald-Sprengle type (MaHaRaNa, Instruments MFG-Company, Ajmer, India) with accuracy of $\pm 0.1 \mathrm{~K}$. The viscometer was calibrated with triple distilled water. Viscosity values were determined using the relation,

$\eta=\rho(K t-L / t)$

where, $\eta$ is a viscosity, $\rho$ is the density of the liquid, $t$ is the flow time and $K$ and $L$ are constants for given viscometer. The flow time was measured with digital stop watch with accuracy of \pm $0.01 \mathrm{~s}$. The $\mathrm{K}$ and $\mathrm{L}$ were obtained by measuring the flow time of triple distilled water at temperatures $298.15 \mathrm{~K}, 303.15 \mathrm{~K}$ and $313.15 \mathrm{~K}$. Linear regression analysis of a plot of $\eta \mathrm{t} / \mathrm{d}$ against $\mathrm{t}^{2}$ for distilled water at three temperatures provided estimates of $\mathrm{K}=2.56 \mathrm{x} 10^{-5} \mathrm{~cm}^{2} \mathrm{~s}^{-2}$ and $\mathrm{L}=-0.12986 \mathrm{~cm}^{2}$. Linear regression coefficient for distilled water was 0.97125 . The value of parameters of pure acetone determined at three temperatures were $\mathrm{K}=1.2 \times 10^{-5} \mathrm{~cm}^{2} \mathrm{~s}^{2}$ and $\mathrm{L}$ $=0.1656 \mathrm{~cm}^{2}$. Linear regression coefficient for pure acetone was 0.96822 . The estimated accuracy of experimental viscosities was $\pm 0.1 \%$.

\section{RESULTS AND DISCUSSION}

Viscosities of both the hydroxamic acids were calculated from equation (1). Measured densities and viscosities data in acetone-water $50 \%(\mathrm{v} / \mathrm{v})$ at $303.15 \mathrm{~K}$ and $313.15 \mathrm{~K}$ are shown in Figures $1-4$, respectively. The viscosities of the solute were obtained as the intercept of the plots of concentration versus viscosity of solutions and indicated in Figure 3 and 4.

The Jones-Dole equation [14] was used to analyse the viscosities of given solutions,

$\eta_{\mathrm{r}}=\eta / \eta_{1}=1+\mathrm{A} c^{1 / 2}+B c$

where $\eta$ is viscosities of the solution and $\eta_{1}$ viscosities of the solvent. A is the coefficient and $c$ is concentration. $B$ is the function of solute-solvent interactions [15]. Hydroxamic acids are nonelectrolyte molecules therefore, A-coefficient becomes zero. This reduces Jones-Dole equation to

$\eta=\eta_{1}(1+\underline{B c})$

The $B$-coefficient obtained as slope of straight line has been recorded in Table 1. Einstein [16] proposed an equation,

$\eta=\eta_{1}(1+2.5 \mathrm{v})$

which describes the concentration dependence of the relative viscosity of solution of nonelectrolyte. In this equation $v$ is the aggregate volume $(1 \mathrm{~mL})$ of the solution. The coefficient of $v$ is $2.5 \mathrm{v}$. The term 2.5 vis taken to be valid for non-electrolyte and it is equivalent to the product in $B c$ the Jones-Dole equation. The value of $B c$ and 2.5 yobtained are nearly of same magnitude as shown in the Table 1 . For the present system these are positive indicating the solute-solvent interactions are strong. 


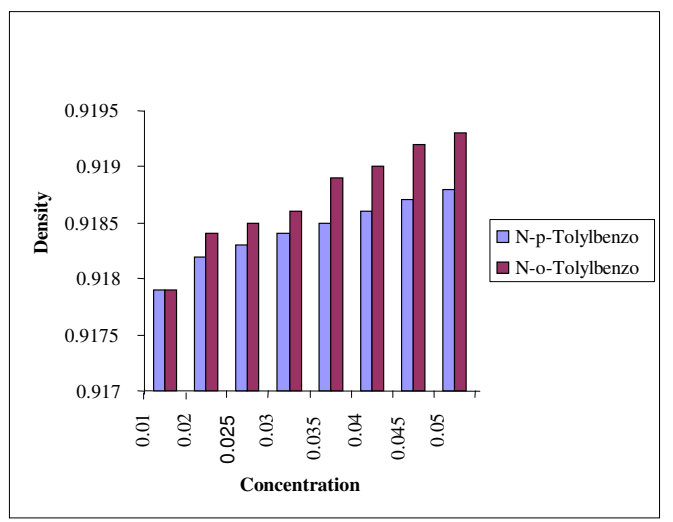

Figure 1. Densities ( $\rho)$ of hydroxamic acids in $50 \%(\mathrm{v} / \mathrm{v})$ acetone-water at $303.15 \mathrm{~K}$.

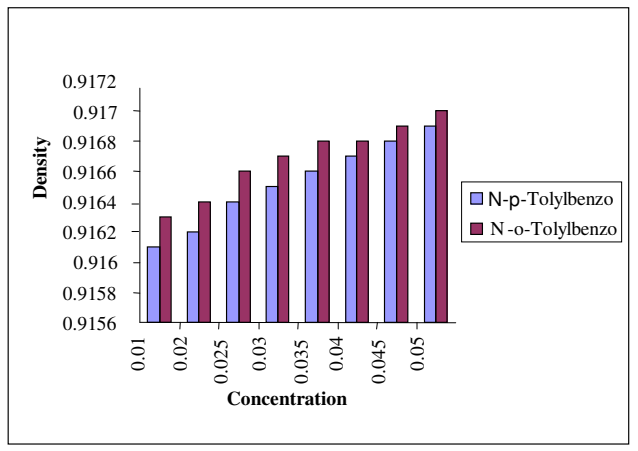

Figure 2. Densities $(\rho)$ of hydroxamic acids in $50 \%(\mathrm{v} / \mathrm{v})$ acetone-water at $313.15 \mathrm{~K}$.

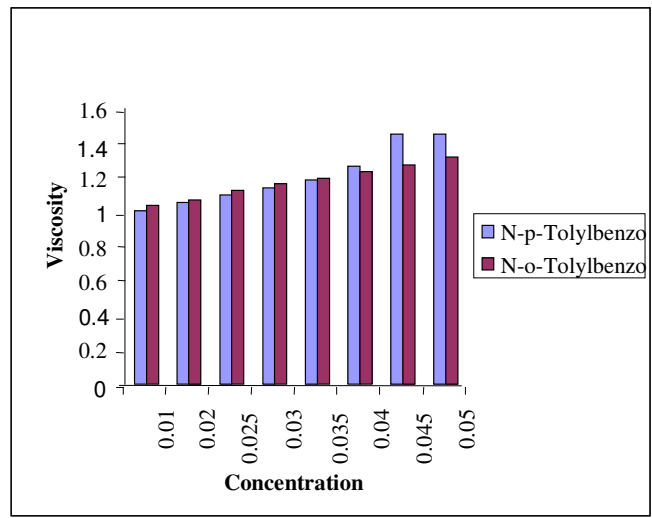

Figure 3. Viscosities $(\eta)$ of hydroxamic acids in $50 \%$ (v/v) acetone-water at $303.15 \mathrm{~K}$. 


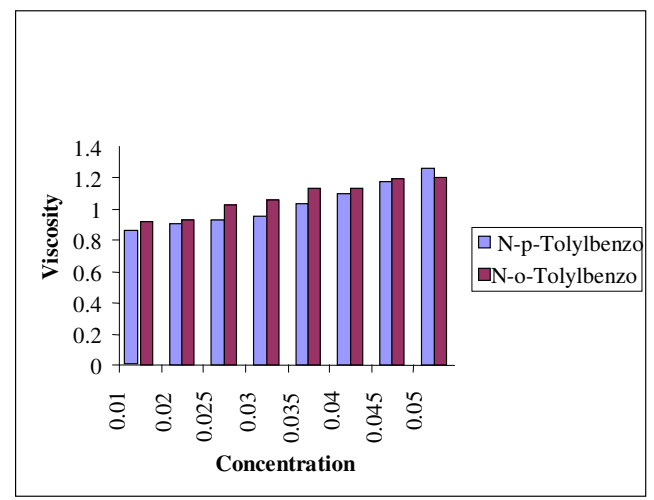

Figure 4. Viscosities ( $\eta$ ) of hydroxamic acids in $50 \%(\mathrm{v} / \mathrm{v})$ acetone-water at $313.15 \mathrm{~K}$.

Table 1. Value of $B \mathrm{c}, 2.5 \mathrm{v}$ and $B$-coefficent of hydroxamic acids in $50 \%(\mathrm{v} / \mathrm{v})$ actone-water.

\begin{tabular}{|c|c|c|c|c|c|c|}
\hline \multirow[t]{2}{*}{ Conc. (M) } & \multicolumn{2}{|c|}{$B c$} & \multicolumn{2}{|c|}{$2.5 \mathrm{v}$} & \multicolumn{2}{|c|}{$B$} \\
\hline & $303.15 \mathrm{~K}$ & $313.15 \mathrm{~K}$ & $303.15 \mathrm{~K}$ & $313.15 \mathrm{~K}$ & $303.15 \mathrm{~K}$ & $313.15 \mathrm{~K}$ \\
\hline \multicolumn{7}{|c|}{$\mathrm{N}-p$-Tolylbenzohydroxamic acid } \\
\hline 0.0000 & - & - & - & - & \multirow{9}{*}{10.9734} & \multirow{9}{*}{13.4602} \\
\hline 0.0100 & 0.0144 & 0.8933 & 0.0144 & 0.8933 & & \\
\hline 0.0200 & 0.0599 & 0.1561 & 0.0599 & 0.1561 & & \\
\hline 0.0250 & 0.1057 & 0.1896 & 0.1057 & 0.1896 & & \\
\hline 0.0300 & 0.1452 & 0.2220 & 0.1452 & 0.2220 & & \\
\hline 0.0350 & 0.1939 & 0.3261 & 0.1939 & 0.3261 & & \\
\hline 0.0400 & 0.2698 & 0.4072 & 0.2698 & 0.4072 & & \\
\hline 0.0450 & 0.3552 & 0.5072 & 0.3552 & 0.5072 & & \\
\hline 0.0500 & 0.4551 & 0.6225 & 0.4551 & 0.6225 & & \\
\hline \multicolumn{7}{|c|}{ N-o-Tolylbenzohydroxamic acid } \\
\hline 0.0000 & - & - & - & - & \multirow{9}{*}{7.2835} & \multirow{9}{*}{9.3836} \\
\hline 0.0100 & 0.0404 & 0.18672 & 0.0404 & 0.18672 & & \\
\hline 0.0200 & 0.0772 & 0.25352 & 0.0772 & 0.25352 & & \\
\hline 0.0250 & 0.1257 & 0.30990 & 0.1257 & 0.30990 & & \\
\hline 0.0300 & 0.1653 & 0.35131 & 0.1653 & 0.35131 & & \\
\hline 0.0350 & 0.2003 & 0.40693 & 0.2003 & 0.40693 & & \\
\hline 0.0400 & 0.2389 & 0.45852 & 0.2389 & 0.45852 & & \\
\hline 0.0450 & 0.2784 & 0.51300 & 0.2784 & 0.51300 & & \\
\hline 0.0500 & 0.3219 & 0.54369 & 0.3219 & 0.54369 & & \\
\hline
\end{tabular}

\section{Activation parameter}

The viscosity data have also been analyzed on the basis of a transition state theory of relative viscosity as suggested by Feakins et al. [17]. The viscosity $B$-coefficient is expressed by equation,

$$
B=\left(\mathrm{V}_{1}^{0}-\mathrm{V}_{2}^{0}\right) / 1000+\mathrm{V}_{1}^{0}\left[\Delta \mu_{1}^{0 \neq}{ }^{0 \neq}-\Delta \mu_{2}{ }^{0 \neq}\right] \mathrm{RT} / 1000
$$


where, $\mathrm{V}_{1}{ }^{0}$ and $\mathrm{V}_{2}{ }^{0}$ are the partial molar volume of the mixed solvent and solute, respectively. The values of partial molar volume are obtained by the relation

$\mathrm{V}=\left(\mathrm{X}_{1}^{0} \mathrm{M}_{1}^{0}+\mathrm{X}_{2}^{0} \mathrm{M}_{2}{ }^{0}\right) / \rho$

where $\mathrm{X}_{1}{ }^{0} \mathrm{M}_{1}{ }^{0}$ and $\mathrm{X}_{2}{ }^{0} \mathrm{M}_{2}{ }^{0}$ are the mole fraction and molecular weight of mixed solvent and solute, respectively. The values of $\mathrm{V}$ are given in Table 4.

$\Delta \mu_{2}{ }^{0 \neq}$. is the contribution per mole of solute to the Gibb's free energy change of activation of viscous flow of the solution. $\Delta \mu_{2}{ }^{0 \neq}$ and $\Delta \mu_{1}^{0 \neq}$. were calculated from the following expressions,

$\Delta \mu_{1}^{0 \neq}=\mathrm{RT} \ln \left(\eta \mathrm{V}_{2}^{0} / \mathrm{hN}\right)$

$\Delta \mu_{2}^{0 \neq}=\Delta \mu_{1}^{0 \neq}+\left(\mathrm{RT} / \mathrm{V}_{2}^{0}\right)\left[1000 B-\left(\mathrm{V}_{1}{ }^{0}-\overline{\mathrm{V}}_{2}{ }^{0}\right)\right]$

where $\mathrm{R}$ is the gas constant, $\mathrm{T}$ is temperature, $\mathrm{h}$ is Planck's constant and $\mathrm{N}$ is Avogadro's number, respectively. The values of $\Delta \mu_{1}^{0 \neq}$ and $\Delta \mu_{2}{ }^{0 \neq}$ are listed in Table 2.

Table 2. Activation parameter of hydroxamic acids in $50 \%(\mathrm{v} / \mathrm{v})$ acetone-water.

\begin{tabular}{|l|l|l|l|l|}
\hline \multirow{2}{*}{ Conc. (M) } & \multicolumn{2}{|c|}{$\Delta \mu_{1}^{0 \neq}\left(\mathrm{kJ}^{\mathrm{m}} \mathrm{mol}^{-1}\right)$} & \multicolumn{2}{c|}{$\Delta \mu_{2}{ }^{0 \neq}\left(10^{3} \mathrm{~kJ}_{\mathrm{mol}}{ }^{-1}\right)$} \\
\cline { 2 - 5 } & $303.15 \mathrm{~K}$ & $313.15 \mathrm{~K}$ & $303.15 \mathrm{~K}$ & $313.15 \mathrm{~K}$ \\
\hline 0.0000 & - & - & - & - \\
\hline 0.0100 & 36.8362 & 37.5363 & 16.6982 & 28.6927 \\
\hline 0.0200 & 37.0305 & 38.0361 & 14.9849 & 19.6715 \\
\hline 0.0250 & 37.1274 & 38.0875 & 14.4016 & 19.3682 \\
\hline 0.0300 & 37.1908 & 38.1468 & 14.0942 & 18.8722 \\
\hline 0.0350 & 37.2471 & 38.3707 & 13.9670 & 18.3450 \\
\hline 0.0400 & 37.3294 & 38.3896 & 13.7682 & 17.8725 \\
\hline 0.0450 & 37.3947 & 38.4669 & 13.6298 & 17.5847 \\
\hline 0.0500 & 37.4991 & 38.5655 & 13.5058 & 17.3641 \\
\hline \multicolumn{5}{|c|}{$\mathrm{N}-o$-Tolylbenzohydroxamic acid } \\
\hline 0.0000 & - & - & - & - \\
\hline 0.0100 & 34.3665 & 34.8506 & 11.2711 & 23.3519 \\
\hline 0.0200 & 36.9948 & 38.0419 & 10.5868 & 14.8932 \\
\hline 0.0250 & 37.0872 & 38.1394 & 10.2047 & 14.1985 \\
\hline 0.0300 & 37.1563 & 38.2253 & 09.8901 & 13.6472 \\
\hline 0.0350 & 37.2140 & 38.3191 & 09.6670 & 13.0433 \\
\hline 0.0400 & 37.3589 & 38.3892 & 09.4588 & 12.7358 \\
\hline 0.0450 & 38.8224 & 38.4457 & 09.4124 & 12.4360 \\
\hline 0.0500 & 38.8607 & 38.6481 & 09.4124 & 12.4366 \\
\hline & & \multicolumn{5}{|c|}{} \\
\hline
\end{tabular}

The activation entropy and enthalpy contributions due to solute were evaluated following the equations,

$-\mathrm{d}\left(\Delta \mu_{2}{ }^{\mathrm{O} \neq}\right) / \mathrm{dT}=\Delta \mathrm{S}_{2}{ }^{\mathrm{O} \neq}$

and

$\Delta \mathrm{H}_{2}{ }^{\mathrm{O} \neq}=\Delta \mu_{2}{ }^{\mathrm{O} \neq}+\mathrm{T} \Delta \mathrm{S}_{2}{ }^{\mathrm{O} \neq}$

The value of solvent and solute activation parameters are given in Table 3. According to Feakins model, the greater the value of $\Delta \mu_{2}{ }^{0 \neq}$ the greater is the structure ability of the solute. The values, $\Delta \mu_{2}{ }^{0 \neq}$ are very large as compared to those of $\Delta \mu_{2}{ }^{0 \neq}$, which suggests that the formation of 
transition state is accompanied by breaking and distortion of inter molecular bonds. The values of $\Delta \mathrm{H}_{2}{ }^{0 \neq}$ and $\Delta \mathrm{S}_{2}{ }^{0 \neq}$ given in Table 4 are negative indicating that the attainment of transition state of viscous flow is accompanied by bond breaking.

Table 3. Activation parameter of hydroxamic acids in $50 \%(\mathrm{v} / \mathrm{v})$ acetone-water.

\begin{tabular}{|c|c|c|c|c|}
\hline \multirow[t]{2}{*}{ Conc. (M) } & \multicolumn{2}{|c|}{$\Delta \mathrm{H}_{2}^{0 \neq}\left(10^{4} \mathrm{~kJ} \cdot \mathrm{mol}^{-1}\right)$} & \multicolumn{2}{|c|}{$\Delta \mathrm{S}_{2}{ }^{0 \neq}\left(10^{2} \mathrm{~kJ} \cdot \mathrm{mol}^{-1} \mathrm{~K}^{-1}\right)$} \\
\hline & $303.15 \mathrm{~K}$ & $313.15 \mathrm{~K}$ & $303.15 \mathrm{~K}$ & $313.15 \mathrm{~K}$ \\
\hline \multicolumn{5}{|c|}{ N-p-Tolylbenzohydroxamic acid } \\
\hline 0.0000 & - & - & - & - \\
\hline 0.0100 & -48.9259 & -89.5620 & -16.6982 & -28.6927 \\
\hline 0.0200 & -43.9134 & -59.6295 & -14.9849 & -19.6715 \\
\hline 0.0250 & -42.2164 & -58.6890 & -14.4016 & -19.3682 \\
\hline 0.0300 & -41.3044 & -57.2042 & -14.0942 & -18.8722 \\
\hline 0.0350 & -40.9230 & -55.5972 & -13.9670 & -18.3450 \\
\hline 0.0400 & -40.3366 & -54.1727 & -13.7682 & -17.8725 \\
\hline 0.0450 & -39.9261 & -53.2933 & -13.6298 & -17.5847 \\
\hline 0.0500 & -39.5747 & -52.2626 & -13.5058 & -17.3641 \\
\hline \multicolumn{5}{|c|}{ N-o-Tolylbenzohydroxamic acid } \\
\hline 0.0000 & - & - & - & - \\
\hline 0.0100 & -33.0373 & -70.7854 & -11.2711 & -23.3513 \\
\hline 0.0200 & -31.0146 & -43.6445 & -10.5868 & -14.8932 \\
\hline 0.0250 & -29.9009 & -43.0161 & -10.2047 & -14.1985 \\
\hline 0.0300 & -28.9925 & -41.3489 & -09.8901 & -13.6472 \\
\hline 0.0350 & -28.3175 & -38.2264 & -09.6670 & -13.0483 \\
\hline 0.0400 & -27.9363 & -38.5904 & -09.5380 & -12.6031 \\
\hline 0.0450 & -27.7018 & -36.9366 & -09.4585 & -12.6031 \\
\hline 0.0500 & -27.5852 & -36.4379 & -09.4124 & -12.4360 \\
\hline
\end{tabular}

Table 4. Molar volume (V) of hydroxamic acids in $50 \%(\mathrm{v} / \mathrm{v})$ acetone-water.

\begin{tabular}{|l|l|l|}
\hline \multirow{2}{*}{ Conc. (M) } & \multicolumn{2}{|c|}{$\mathrm{V}\left(\mathrm{mL} \mathrm{mol}^{-1}\right)$} \\
\cline { 2 - 3 } & $303.15 \mathrm{~K}$ & $313.15 \mathrm{~K}$ \\
\hline \multicolumn{3}{|c|}{$\mathrm{N}-p$-Tolylbenzohydroxamic acid } \\
\hline 0.0000 & 28.2666 & 28.1857 \\
\hline 0.0100 & 28.3181 & 28.2096 \\
\hline 0.0200 & 28.3595 & 28.2699 \\
\hline 0.0250 & 28.3878 & 28.2861 \\
\hline 0.0300 & 28.4239 & 28.3085 \\
\hline 0.0350 & 28.4430 & 28.3324 \\
\hline 0.0400 & 28.4691 & 28.3687 \\
\hline 0.0450 & 28.4989 & 28.3839 \\
\hline 0.0500 & 28.5291 & 28.4095 \\
\hline \multicolumn{3}{|c|}{$\mathrm{N}-o$-Tolylbenzohydroxamic acid } \\
\hline 0.0000 & 28.2666 & 28.1857 \\
\hline 0.0100 & 28.3254 & 28.2089 \\
\hline 0.0200 & 28.3850 & 28.2655 \\
\hline 0.0250 & 28.4154 & 28.2931 \\
\hline 0.0300 & 28.4461 & 28.3049 \\
\hline 0.0350 & 28.4600 & 28.3500 \\
\hline 0.0400 & 28.4912 & 28.3746 \\
\hline 0.0450 & 28.5208 & 28.3824 \\
\hline 0.0500 & 28.5308 & 28.4129 \\
\hline
\end{tabular}

Bull. Chem. Soc. Ethiop. 2007, 21(3) 


\section{Excess properties}

The excess molar volume $\left(\mathrm{V}^{\mathrm{E}}\right)$ for these solutions were obtained by the given expression,

$\mathrm{V}^{\mathrm{E}}=\mathrm{V}-\left(\mathrm{X}_{1} \mathrm{~V}_{1}+\mathrm{X}_{2} \mathrm{~V}_{2}\right)$

where, $\mathrm{V}, \mathrm{V}_{1}$ and $\mathrm{V}_{2}$ are the molar volume of solution, mixed solvent and solute, respectively. It is well known that negative excess molar volume arises due to increased interaction between the unlike molecules [18]. The molar volumes for mixed solvent are 28.266 and 28.185, respectively. The molar volumes of solution are given in Table 4 . The molar volume of solutes are 247.37, 239.86 for N-p-tolylbenzohydroxamic acid and 247.86, 240.80 for N-o-tolylbenzohydroxamic acid at $303.15 \mathrm{~K}$ and $313.15 \mathrm{~K}$, respectively.

The excess viscosity $\left(\eta^{\mathrm{E}}\right)$ have been evaluated from the observed viscosity of the solution and that of its pure components using the relation,

$\eta^{\mathrm{E}}=\eta-\left(X_{1} \eta_{1}+X_{2} \eta_{2}\right)$

where, $\eta, \eta_{1}$ and $\eta_{2}$ are the viscosities of solution, mixed solvent and solute, respectively. The data are listed in Table 5.

Table 5. Excess viscosity $\left(\eta^{\mathrm{E}}\right)$ and excess molar volume $\left(\mathrm{V}^{\mathrm{E}}\right)$ of hydroxamic acid.

\begin{tabular}{|l|l|l|l|l|}
\hline \multirow{2}{*}{ Conc. (M) } & \multicolumn{2}{|c|}{$\mathrm{V}^{\mathrm{E}}$} & \multicolumn{2}{c|}{$\eta^{\mathrm{E}}$} \\
\cline { 2 - 5 } & $303.15 \mathrm{~K}$ & $313.15 \mathrm{~K}$ & $303.15 \mathrm{~K}$ & $313.15 \mathrm{~K}$ \\
\hline 0.0000 & - & - & - & - \\
\hline 0.0100 & -0.0020 & -0.0419 & 0.0062 & 0.1973 \\
\hline 0.0200 & -0.0030 & -0.0441 & 0.0253 & 0.2494 \\
\hline 0.0250 & -0.0033 & -0.0500 & 0.0437 & 0.2755 \\
\hline 0.0300 & -0.0028 & -0.0584 & 0.0589 & 0.3000 \\
\hline 0.0350 & -0.0044 & -0.0639 & 0.0770 & 0.3819 \\
\hline 0.0400 & -0.0014 & -0.0678 & 0.1038 & 0.4453 \\
\hline 0.0450 & -0.0047 & -0.0691 & 0.1321 & 0.5235 \\
\hline 0.0500 & -0.0050 & -0.0872 & 0.1630 & 0.6148 \\
\hline \multicolumn{5}{|c|}{$\mathrm{N}-o-$ Tolylbenzohydroxamic acid } \\
\hline 0.0000 & - & - & - & - \\
\hline 0.0100 & -0.0020 & -0.0380 & 0.0443 & 0.1457 \\
\hline 0.0200 & -0.0070 & -0.0430 & 0.0769 & 0.1978 \\
\hline 0.0250 & -0.0110 & -0.0260 & 0.1291 & 0.2417 \\
\hline 0.0300 & -0.0130 & -0.0630 & 0.1647 & 0.2740 \\
\hline 0.0350 & -0.0240 & -0.0470 & 0.1996 & 0.3174 \\
\hline 0.0400 & -0.0260 & -0.0580 & 0.2381 & 0.3577 \\
\hline 0.0450 & -0.0280 & -0.0760 & 0.2773 & 0.4139 \\
\hline 0.0500 & -0.0460 & -0.0140 & 0.3208 & 0.4261 \\
\hline
\end{tabular}

The impact of solute on viscosity is understood in terms of the parameter d, regarded as a measure of the strength of interaction between components of solution. It has been estimated using relationship proposed by Gruenberg and Nissan [19],

In $\eta=X$ In $\eta_{1}+X$ In $\eta_{2}+X_{1} X_{2} d$

where $\mathrm{d}$ is the parameter proportional to W/RT, W is the interchange energy or a measure of interactions. It is observed that values of $d$ and $\eta^{\mathrm{E}}$ are positive suggesting complex formation involving mixed solvent. 
The extra thermodynamic property, excess Gibb's free energy of activation of flow $\left(\mathrm{G}^{\mathrm{E}}\right)$ for the solution have been computed from the Erying equation [20],

$\mathrm{G}^{\mathrm{E}}=\mathrm{RT}\left[\operatorname{In} \eta \mathrm{V}-\left(\mathrm{X}_{1} \operatorname{In} \eta_{1} \mathrm{~V}_{1}+\mathrm{X}_{2}\right.\right.$ In $\left.\left.\eta_{2} \mathrm{~V}_{2}\right)\right]$

The positive value of $\mathrm{G}^{\mathrm{E}}$ indicates the presence of strong interactions between the solute and mixed solvent accompanied by the complex formation. The values of $d$ and $G^{E}$ are reported in Table 6. The value of $\mathrm{G}^{\mathrm{E}}$ increases with increase in concentration of solute and also increases with increase in temperature suggesting the interaction becomes more and more stronger.

Table 6. Interaction parameters of Gurnberg and Nissan $(d)$ and excess Gibb's free energy $\left(\mathrm{G}^{\mathrm{E}}\right)$.

\begin{tabular}{|l|l|l|c|c|}
\hline \multirow{2}{*}{ Conc. (M) } & \multicolumn{3}{|c|}{$\mathrm{d}$} & $\mathrm{G}^{\mathrm{E}}\left(10^{2}\right)$ \\
\cline { 2 - 5 } & $303.15 \mathrm{~K}$ & $313.15 \mathrm{~K}$ & $303.15 \mathrm{~K}$ & $313.15 \mathrm{~K}$ \\
\hline \multicolumn{5}{|c|}{$\mathrm{N}-p$-Tolylbenzohydroxamic acid } \\
\hline 0.0000 & - & - & - & - \\
\hline 0.0100 & 22.1078 & 131.8771 & 4.5736 & 27.5121 \\
\hline 0.0200 & 44.7251 & 111.6700 & 18.3281 & 46.7035 \\
\hline 0.0250 & 61.6903 & 106.7472 & 31.5397 & 55.9291 \\
\hline 0.0300 & 69.1444 & 102.0938 & 42.3982 & 64.2686 \\
\hline 0.0350 & 77.5062 & 109.2391 & 47.1601 & 90.9439 \\
\hline 0.0400 & 91.9945 & 132.2163 & 74.9108 & 110.2748 \\
\hline 0.0450 & 103.3392 & 137.5965 & 95.3500 & 132.3668 \\
\hline 0.0500 & 114.0383 & 149.9408 & 117.7206 & 156.5710 \\
\hline \multicolumn{5}{|c|}{$\mathrm{N}-o$-Tolylbenzohydroxamic acid } \\
\hline 0.0000 & - & - & - & - \\
\hline 0.0100 & 61.5145 & 263.6711 & 12.3233 & 54.5905 \\
\hline 0.0200 & 57.2972 & 174.3782 & 23.1925 & 72.2237 \\
\hline 0.0250 & 93.6509 & 165.9143 & 38.8381 & 86.3540 \\
\hline 0.0300 & 77.9236 & 156.1452 & 47.7337 & 96.3672 \\
\hline 0.0350 & 73.4618 & 149.5809 & 57.0112 & 109.3788 \\
\hline 0.0400 & 93.4673 & 145.2054 & 66.9843 & 121.1746 \\
\hline 0.0450 & 83.2692 & 148.1073 & 76.8529 & 136.6061 \\
\hline 0.0500 & 85.2568 & 134.9908 & 87.3567 & 139.3960 \\
\hline
\end{tabular}

\section{AKNOWLEDGEMENTS}

The authors are thankful to the Head, School of Studies in Chemistry, Pt. Ravishankar Shukla University, Raipur (C.G.), for providing laboratory facilities.

\section{REFERENCES}

1. White, E.C.; Hill, T.H. J. Bacteriol. 1943, 45, 433.

2. Pande, R.; Tondon, S.G. J. Chem. Engg. Data 1979, 24, 72.

3. Loayza-Muro, R.; Figueroa, C.C.; Niemeyer, H.M. J. Chek. Ecol. 2000, 26, 2725.

4. Mukan Ganyama, S.; Figueroa, C.C.; Hasler, J.A.; Niemeyer, H.M. J. Insect. Physiol. 2003, 49, 223.

5. Tays, K.; Atkinson, J. Synth. Commun. 1998, 28, 903.

6. Petho, M. Novengtermeles 2000, 49, 227.

7. Nikus, J.; Daniel, G.; Jonsson, L.M.V. Physiol. Plant 2001, 111, 466. 
8. Jang, I.C. Pahk, Y.M. Song, S.I., Kwon, H.J.; Nahm, B.H., Kim, J.K. Plant J. 2003, 33, 531.

9. Biou, V; Damas, R.; Cohen Addad, C.; Douce, R.; Job, D.; Pebay-Peyroula, E. Embo J. 1997, 16, 3405.

10. Nicol, O.; Wratten, S.D. Ann. Appl. Biol. 1997, 130, 387.

11. Tadenama, M.; Takahashi, K.; Sato, S. J. Soc. Brewing Japan 1966, 61, 941.

12. Richardon, M.O.; Bacon, C.W. J. Chem. Ecol. 1993, 19, 1613.

13. Vanjari, H; Pande, R. J. Mol. Liq. 2003, 108, 257.

14. Nikam, S.P.; Sawant, B.A. Bull. Chem. Soc. Jpn. 1998, 71, 2055.

15. Jones, G.; Dole, M.J. Am. Chem. Soc. 1929, 51, 2950.

16. Feakins, D.; Freemantle, K.G.; Lawerence. J. Chem. Soc. Faraday Trans. 1974, 70, 795.

17. Aralaguppi, I.M.; Aminabhavi, M.T.; Balandi, H.R.; Joshi, S.S. J. Phy. Chem. 1991, 95, 5299.

18. Zhao, C.; Maj P.; Li, J. J. Chem. Thermo. 2005, 37, 37.

19. Granberg, L.; Nissan, A.H. Nature (London) 1949, 164, 799.

20. Grunberg, L. Trans Faraday Soc. 1954, 50, 1293. 